\title{
Evaluation of Sea-Water Intrusion in Coastal Aquifers Using both Numerical Methods and Causal Research: A Case Study of Mombasa, Kenya
}

\author{
Dorcas Mutheu Musingi', Michael Mbindyo Munywoki², Benjamin Musyimi Musingi,4 \\ ${ }^{1}$ Department of Building and Civil Engineering Water Section, Technical University of Mombasa, Mombasa, Kenya \\ ${ }^{2}$ Department of Mathematics, Technical University of Mombasa, Mombasa, Kenya \\ ${ }^{3}$ Animal Breeding and Genomics Group, Department of Animal Sciences, Egerton University, Egerton, Kenya \\ ${ }^{4}$ Department of Biological Sciences, Egerton University, Egerton, Kenya \\ Email:dmmutheu@yahoo.com
}

How to cite this paper: Musingi, D.M., Munywoki, M.M. and Musingi, B.M. (2021) Evaluation of Sea-Water Intrusion in Coastal Aquifers Using both Numerical Methods and Causal Research: A Case Study of Mombasa, Kenya. Engineering, 13, 388-398. https://doi.org/10.4236/eng.2021.137028

Received: May 1, 2021

Accepted: July 13, 2021

Published: July 16, 2021

Copyright ( 2021 by author(s) and Scientific Research Publishing Inc. This work is licensed under the Creative Commons Attribution International License (CC BY 4.0).

http://creativecommons.org/licenses/by/4.0/

(c) (i) Open Access

\begin{abstract}
This research carried out in Mombasa Island links research done in 2020 on the effects of sea-water intrusion and the current state. The aquifer in Mombasa Island is semi-confined and consists of limestone and coral rock. Water samples were collected and tested from 32 boreholes to determine chemical qualities. Results showed that chloride levels ranged from $74 \mathrm{mg} / \mathrm{l}$ to 412 $\mathrm{mg} / \mathrm{l}$, with $34 \%$ of boreholes having high chloride concentration. After modelling using MT3D program results indicated that the boreholes near the ocean were interfered by sea-water intrusion because chloride concentration was high. Control measures to prevent further sea-water intrusion should be put in place. Therefore, from a practical point of view, individuals who have sunk boreholes since 2020 try to mitigate the problem by installing Reverse Osmosis systems within their facilities, to reduce chloride levels from borehole water. The current research analyses the impact of intrusion on the installed RO systems on Mombasa Island, including cost implications, with the view of proposing viable mitigation measures. The reverse osmosis system though expensive would save a lot of chloride entering the bore holes. It is a little bit expensive though but the end results are positive and the chloride levels will reduce the cost of using too much soap.
\end{abstract}

\section{Keywords}

Seawater Intrusion, Mombasa Island, RO Systems 


\section{Introduction}

\section{Background of the Problem}

An aquifer is a geologic formation that stores and transmits water. An aquifer may be confined, semi-confined, perched or unconfined. The aquifer in Mombasa Island considered in this study is Semi-Confined also called Leaky aquifer. This aquifer is characterized by fractured limestone rock material which was made by the direct lithification of coral reefs, sea organic shells, or marine animal skeletons. Fractured limestone can allow both horizontal and vertical movement of water within and through an aquifer during pumping, thus a semi-confined or leaky aquifer. Water in aquifers is carried to the surface naturally through a spring or can be discharged into lakes and streams. This water can also be hauled out through a borehole drilled into the aquifer [1].

Under natural conditions, groundwater is normally discharged into the ocean where the aquifers come into contact with the ocean due to the hydraulic gradient. With increased population and industrialization within the town precincts, groundwater demands in such coastal areas can also increase. With these increased demands, the seaward flow of groundwater can be reduced or even reversed due to a landward hydraulic gradient, causing sea-water to penetrate inland in aquifers. This phenomenon is known as sea-water intrusion [2]. Thus sea-water intrusion into groundwater formations is partly due to human activities such as abstraction and damage caused to natural barriers to sea-water intrusion. Groundwater supplies become less useful when the sea-water travels inland to good fields; moreover, the aquifer becomes contaminated with salts. Protecting coastal aquifers from sea-water intrusion is important if future use of fresh groundwater is deemed necessary [3].

Sea-water is not consistently saline throughout the world. Averagely, sea-water in the biosphere's oceans has a salinity of about 3.5\%. Meaning that for every one liter of sea-water there are 35 grams of salts (commonly sodium chloride) dissolved in it. Water with this level of salinity is not potable. Sea-water has a density about $1.025 \mathrm{~g} / \mathrm{cm}^{3}$ while fresh groundwater has a density of approximately 1 $\mathrm{g} / \mathrm{cm}^{3}$ [4]. Typically, the concentration of chloride ions in water is used to identify seawater intrusion. Sea-water intrusion may occur in coastal areas, whereas up coning is the rise of freshwater sea-water interface below the well in response to drawdown of the water table around the well, sea-water intrusion always increases the volume of sea-water stored underground and may finally lead to salinization of the entire aquifer [5].

Population and industrialization growth within Mombasa Island have resulted in increased water demands. Due to this increased water demand, residents in Mombasa Island have thus drilled boreholes from which they abstract water to substitute the frequent water shortages from the main pipeline. There are chances that abstraction may be surpassing recharge, hence causing depletion of groundwater, and resulting in seawater intrusion. A study was carried in the year 2004 which demonstrated the problem of seawater intrusion in Mombasa Island. Therefore, this paper is aimed at demonstrating the effects of seawater intrusion 
in coastal aquifers using both Numerical Technique and Causal research. The paper will demonstrate the impacts of seawater intrusion in both monetary and social value within the coast region.

\section{Materials and Methods}

Mombasa Island has a high demand for groundwater due to frequent shortages of supply from Mombasa Water and Sewerage Company. The groundwater abstraction from the aquifer has exceeded recharge and this has a serious consequence on future availability of groundwater and can also lead to land subsidence. Lowering of groundwater level due to large abstractions has motivated sea-water intrusion in the aquifer and hence lowered the groundwater quality and usability for human consumption. This has resulted in Mombasa Residents resulting to use of reverse Osmosis Systems to reduce the effects of saline water on daily water use. A decrease in groundwater level due to excessive abstraction causes permanent damage to the stability of the groundwater storage and facilitates sea-water migration and the pollution of the aquifers with sea-water [6].

This paper develops a model that represents seawater intrusion into coastal aquifer. Thereby giving us the capability for simulating the behavior of the hydrologic and water quality components, that can be used for future planning and development. It was assumed Chloride concentration in Groundwater within Mombasa Island is only due to proximity of the aquifer to the ocean.

The broad objective of this research was to demonstrate the effects of sea-water intrusion into Mombasa coastal aquifer.

The study was carried out with the following specific aims; to investigate the aquifer characteristics of the area of study, to investigate the levels of sea-water intrusion into the aquifer in 20 years, to assess the financial impact of reverse osmosis plants within the Coast region.

The finite-difference numerical technique was applied in this study. MODFLOW is a general finite-difference groundwater flow model developed by the US Geological Survey as an integrated and extensible recreation tool for modeling groundwater flow and is applied in this study. Boundary conditions in this study were specified as fixed-head because the ocean surrounds the Island with a fixed hydraulic head of Zero. SURFER computer program was chosen in interpolating raw data to allow data to be input to MODFLOW in the right format.

Sampling was done randomly in each estate within the Mombasa Island with the main objective of having a maximum distance between boreholes not exceeding one kilometer. 32 boreholes were sampled. Mombasa Island had approximately 100 boreholes as found in the Ministry of Water Development records in Nairobi in the year 2004. The boreholes sampled were thus $32 \%$ of the whole population. The criterion used to get a representative number of the boreholes was as follows; the density of boreholes per estate within the Island, availability of data as pertains to the boreholes. This data includes aquifer characteristics at a particular borehole, water rest levels, and water struck levels and 
accessibility to the boreholes.

Samples obtained from selected boreholes were then taken to the laboratory for testing of solutes.

The reverse osmosis data was sampled from 100 out of 143 customers served by Davis and Shirtliff Limited which deals with the installation of these Reverse Osmosis Systems among other activities.

\section{Results and Discussions}

\subsection{Chloride Concentration}

Figure 1 shows that chloride is moving from the sea towards the island at different rates in different areas. The chloride concentration levels are ranging from 50 to $350 \mathrm{mg} / \mathrm{l}$ within the Island. It was noted that the concentration of chloride is low approximately at the center of the Island. The contour lines in the Figure are joining areas of the same chloride concentration (Figure 2).

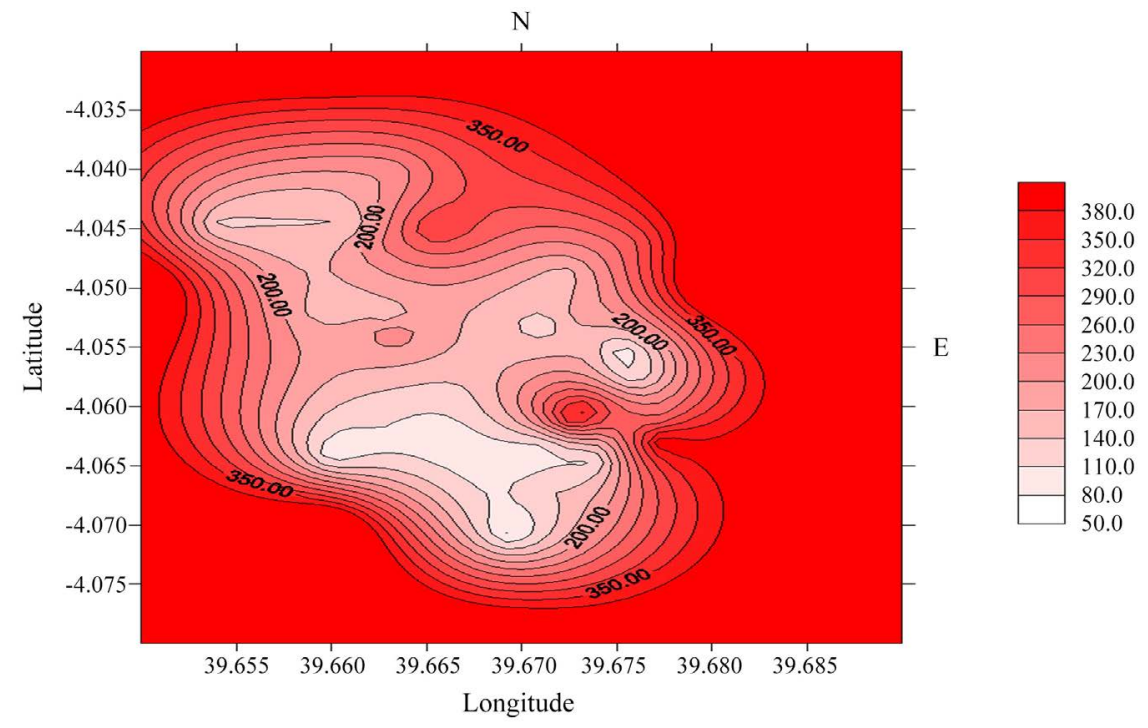

Figure 1. Chloride concentration (mg/l) plot.

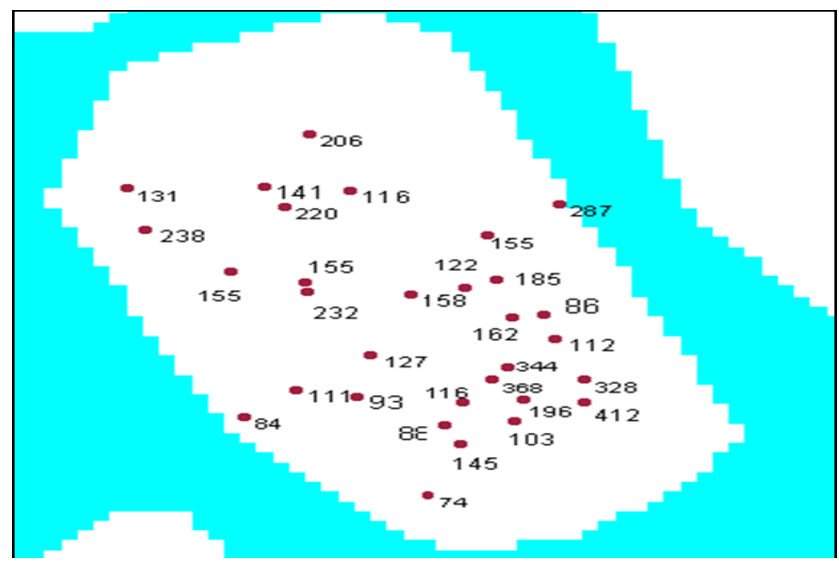

Figure 2. Arc view posted chloride concentration in boreholes $(\mathrm{mg} / \mathrm{l})$. Borehole's chloride concentration:

; Ocean: 
From this research, it was found out that Mombasa Island consists of one confined leaky aquifer ranging from negative seven from sea level to nine meters above sea level and mainly of limestone rock with the permeability of $1 \mathrm{~mm} / \mathrm{day}$ and effective porosity of $30 \%$.

\subsection{Levels of Sea-Water Intrusion into the Aquifer}

Movement of chloride was modeled using MT3D to demonstrate the current concentration of chloride within Mombasa Island and its propagation with time.

Observations boreholes, during modeling, were set to monitor the movement of chloride to produce a graphical presentation of the movement of the solute. Observation times were specified in ascending order up to 20 years.

The upper curves show observation wells near the ocean. These wells near the ocean will be polluted faster with more chloride saturation. After sixteen years, the concentration of chloride in the wells will be the same as that in the ocean because of the continuous flow of solutes from a region of high concentration to a low concentration area through hydrodynamic dispersion (Figure 3, Figure 4).

From the results found and fitted by regression, it is possible to predict chloride concentration by an equation. The underlying chemistry of sea-water intrusion and other properties show that sea-water intrusion follows a polynomial equation. Polynomial equations of order six were chosen in the prediction of an increase of chloride concentration with time in boreholes within Mombasa Island (Figure 5).

The polynomial equation is specific for each borehole, and each borehole is located using coordinates. Validation entailed comparison of observed and simulated chloride concentration one year after initial sampling (Figure 6).

\subsection{The Financial Impact of Reverse Osmosis Systems in the Coastal Region}

The reverse osmosis data was sampled from 100 out of 143 customers served by Davis and Shirtliff Company Limited which deals with the installation of reverse osmosis systems.

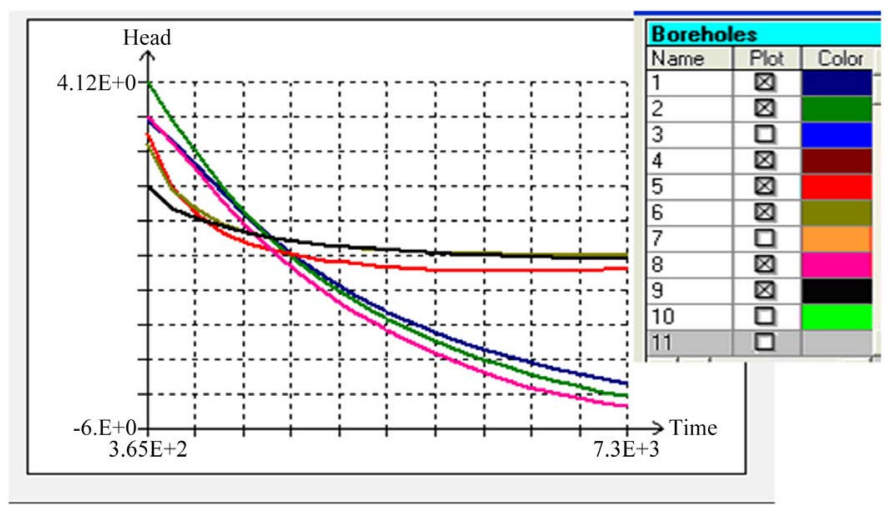

Figure 3. Head time curves. Note: The boxes with the cross (X) indicate the plotted curves in the key Boxes without cross indicate observation boreholes not plotted. The $\mathrm{x}$-axis is in days and the $\mathrm{y}$-axis is in $\mathrm{mg} / \mathrm{l}$. 


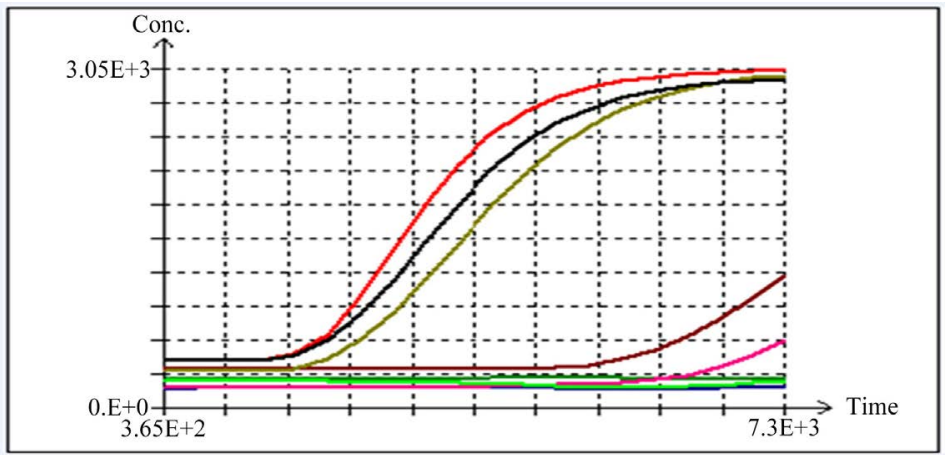

Figure 4. Chloride concentration curves.

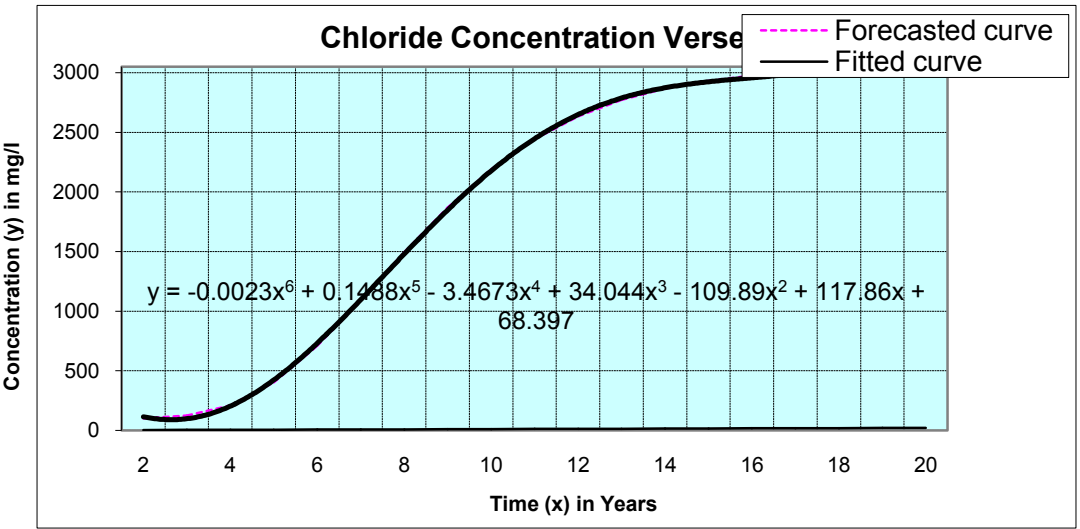

Figure 5. Polynomial equation for chloride concentration approximation.

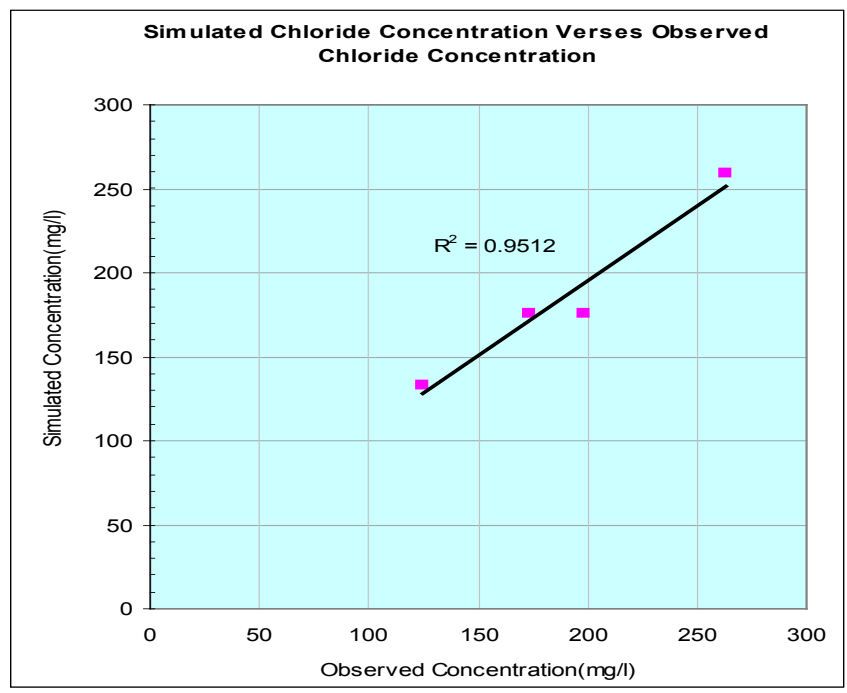

Figure 6. Comparison of one year observed and simulated chloride concentration $(\mathrm{mg} / \mathrm{l})$.

\subsubsection{Capacity of RO Systems}

Figure 7 shows the general capacity of the reverse osmosis systems installed within the coastal region in litres per hour. Most of the systems accommodate 1000 litres per hour which is showed by color yellow on the graph followed by a capacity of 500 litres per hour represented on the graph as color grey. 


\subsubsection{Investment Cost of RO Systems}

Figure 8 shows investment cost in Kenya shillings. The most used amount for installation represented in white is 1.4 million Kenya shillings per RO system. However the total cost for installation of 100 machines is approximately 233 million Kenyan shillings which is a costly investment impacting heavily on the coastal economy.

\subsubsection{Service Cost of RO Systems}

Figure 9 below shows the service cost of the installed RO systems per year with most systems servicing at an average cost of 100,000 Kenya shillings per system per year. However the total cost of maintenance for the $100 \mathrm{RO}$ systems is approximately 11 million Kenya shillings annually.

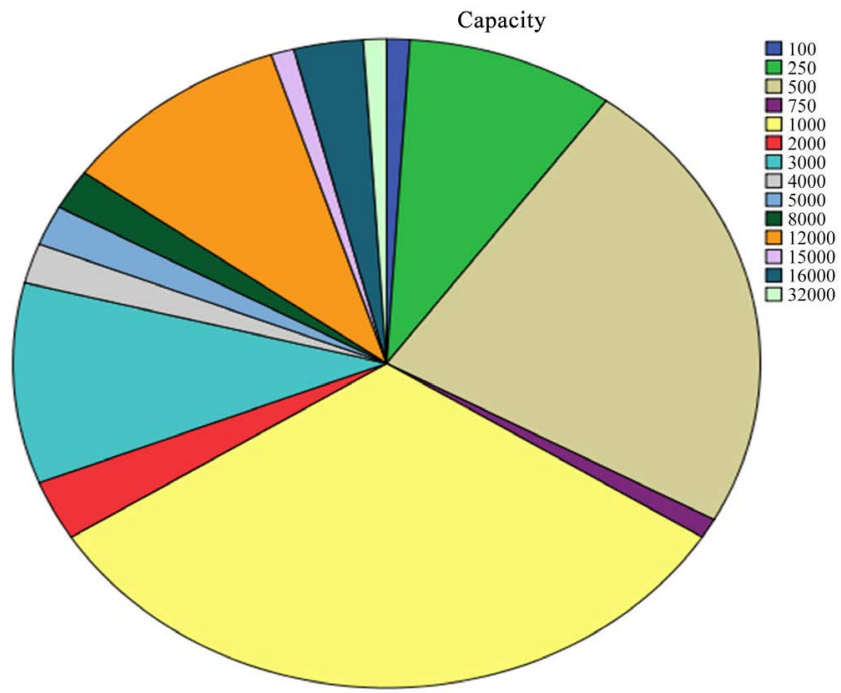

Figure 7. Showing the capacity of the RO systems.

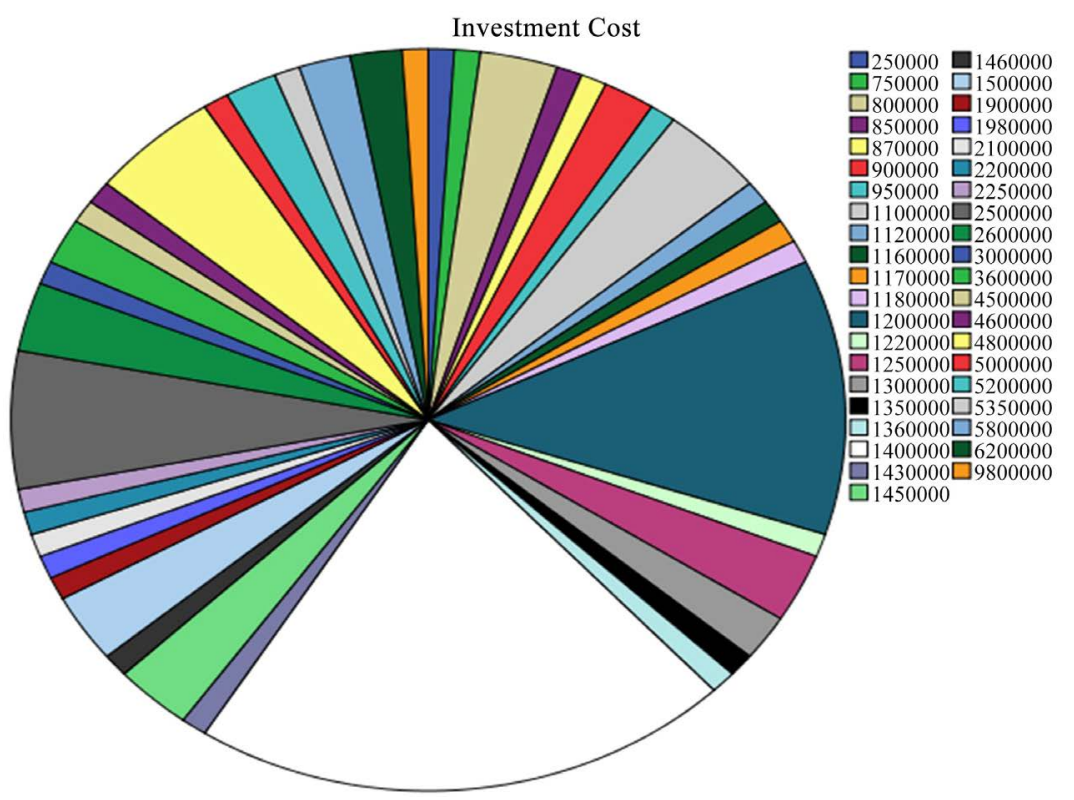

Figure 8. Showing the investment cost of the RO systems. 


\subsubsection{Power Consumption Cost of RO Systems}

Figure 10 shows the power consumption cost per day assuming the RO system works for 8 hours a day. Most systems consumed an average amount of 36,000 Kenyan shillings per day as represented in the graph in color yellow. The total consumption cost per year for 100 RO machines is approximately 12 million Kenyan shillings.

\subsubsection{Mean Investment Cost}

Figure 11 shows a graph of the mean investment cost plotted against capacity. It demonstrates an increase in investment cost as the capacity of the RO systems increases.

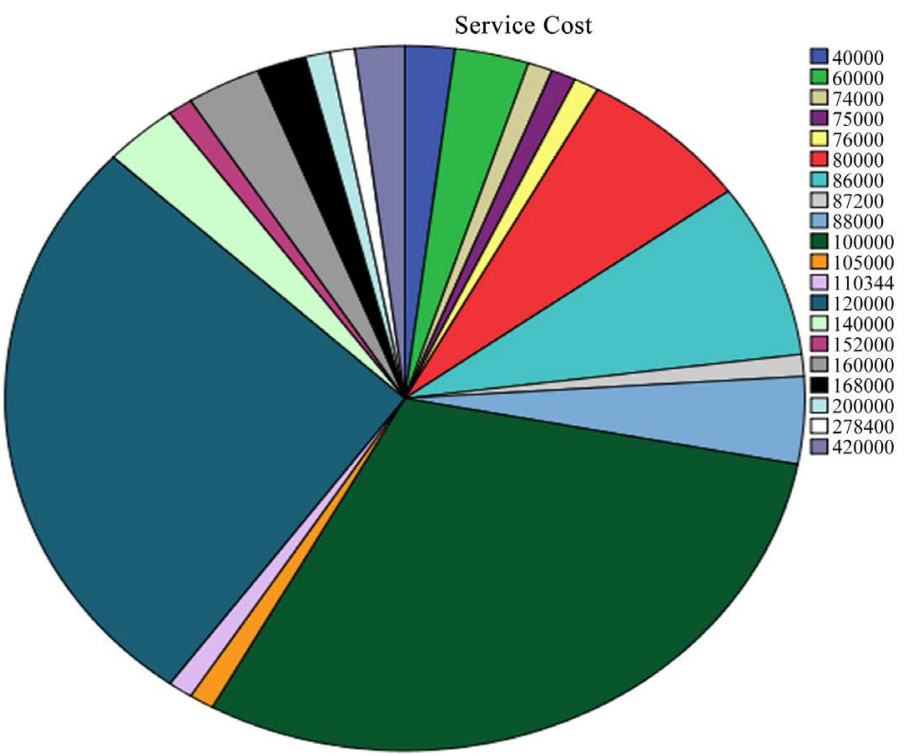

Figure 9. Showing the service cost of the RO systems.

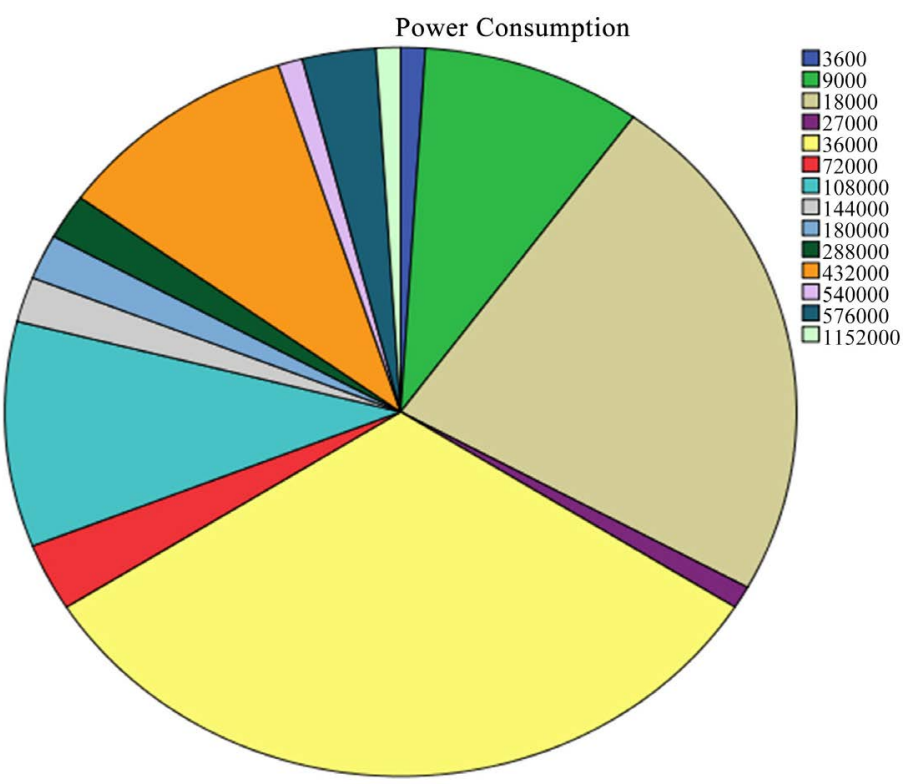

Figure 10. Showing the power consumption cost of the RO systems per day. 


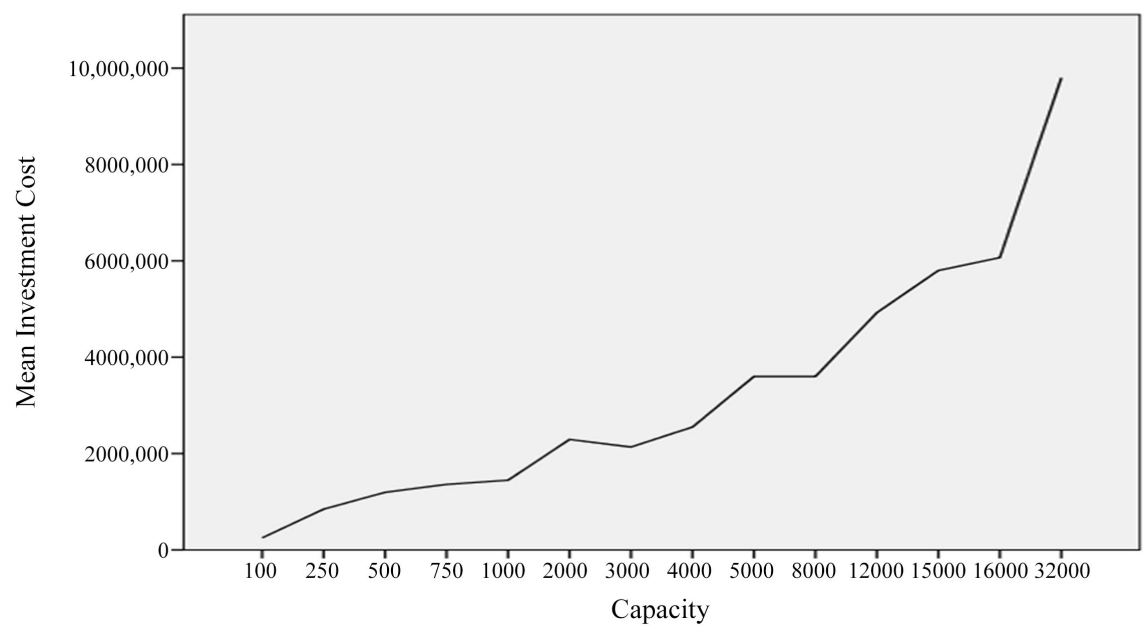

Figure 11. Showing the mean investment cost of the RO systems.

\section{Conclusions}

From the analysis done above, there's clear evidence that there is sea-water intrusion into the Mombasa coastal aquifer. The impact escalated in the year 2012 when the residents were forced to install reverse osmosis systems so as to purify the water. However, this project has been very costly hence impacting on the general economy of the coastal region. Each equipment installed would cost the economy an average of 2,370,715 million Kenyan shillings. These equipments are mostly imported therefore adding into coastal region imports which may result to a trade deficit.

The quality of groundwater in boreholes within Mombasa Island has been interfered with by sea-water intrusion. $34 \%$ of the boreholes contain solutes over the recommended values by WHO Standards which are $250 \mathrm{mg} / \mathrm{l}$ for chloride and $200 \mathrm{mg} / \mathrm{l}$ for sodium.

Mombasa Island is a confined leaky aquifer also called semi-confined aquifer ranging from negative seven from sea level to nine meters above sea level and mainly of limestone rock with the permeability of $1 \mathrm{~mm}$ /day and porosity of approximately $30 \%$. A twenty-year simulation of sea-water intrusion reveals that, through the process known as seawater intrusion, $90 \%$ of Mombasa Island aquifer will be contaminated by solutes from the ocean in 20 years' time. Installation of RO systems has provided a solution to the problem, however, it is quite costly and results in excessive expenditure that impacts the economy negatively.

\section{Recommendations}

From the findings of this research, it is recommended that the drilling of wells should be regulated to reduce excessive groundwater abstraction which is increasing the rate of sea-water intrusion into the Mombasa Island aquifer. This can be achieved by ensuring that there is no more licensing of borehole drilling within the Island. Similarly, strict regulation should be put in place to ensure that all functioning wells within the island are registered to reduce haphazard 
drilling of wells and boreholes.

Another recommendation is that observation wells for monitoring the progress of sea-water intrusion should be drilled in strategic areas to keep track of increasing drawdown which facilitates further sea-water intrusion. These observation boreholes can also be used in monitoring the groundwater quality.

Chemical analysis of existing boreholes should be done frequently to keep track of increasing solutes concentrations. This is because groundwater quality is determined by solutes concentration amongst other things.

There is no current method in practice for controlling sea-water intrusion within Mombasa Island. It is essential to put one in place due to the current condition of groundwater pollution by sea-water thus enhancing sustainable use of groundwater resources. Besides a control method to sea-water intrusion, another source of water should be implemented like rainwater harvesting to supplement groundwater thus avoiding excessive abstraction which leads to further seawater intrusion.

Using fresh-water saline-water interface and hydraulic head time curves, recharge wells should be designed in strategic areas to help in raising the hydraulic head and stop the further seawater intrusion. Other models rather than MODFLOW are required to come up with the best recharge well and fresh-saline groundwater interface.

Another sea-water intrusion control method for Mombasa Island can be by applying the conjunctive use of water. Which means collective use of surface and groundwater systems to augment resource use and minimize adversative effects of using a solitary source where in this case the single source is groundwater.

\section{Acknowledgements}

I would like to take this opportunity to thank all the people who took part in shaping this research paper. I am greatly indebted to my loving husband Mr. Bernard Mutisya for continued social and financial support during the entire period of this research. Special thanks to Prof Eng. Kipkorir for encouraging me to write this paper. Special thanks to both Dr. Diana Mwende for moral support during the process of compiling the report and Dr. Munywoki of Technical University of Mombasa for the support accorded. Lastly, I would like to appreciate Ms. Esther Njoki from the Department of Building and Civil engineering, Technical University of Mombasa whom without her encouragement this paper would have been difficult to accomplish.

\section{Conflicts of Interest}

The authors declare no conflicts of interest regarding the publication of this paper.

\section{References}

[1] Gopinath, S., Srinivasamoorthy, K., Saravanan, K., Suma, C.S., Prakash, R., Senthil- 
nathan, D., et al. (2016) Modeling Saline Water Intrusion in Nagapattinam Coastal Aquifers, Tamilnadu, India. Modeling Earth Systems and Environment, 2, Article No. 2. https://doi.org/10.1007/s40808-015-0058-6

[2] Ketabchi, H., Mahmoodzadeh, D., Ataie-Ashtiani, B. and Simmons, C.T. (2016) Sea-Level Rise Impacts on Seawater Intrusion in Coastal Aquifers: Review and Integration. Journal of Hydrology, 535, 235-255.

https://doi.org/10.1016/j.jhydrol.2016.01.083

[3] Klassen, J. and Allen, D.M. (2017) Assessing the Risk of Saltwater Intrusion in Coastal Aquifers. Journal of Hydrology, 551, 730-745.

https://doi.org/10.1016/j.jhydrol.2017.02.044

[4] Krupavathi, K. and Movva, R.B. (2016) Seawater Intrusion into Coastal Aquifers-Concepts, Methods and Adaptable Control Practices. International Journal of Agricultural Engineering, 9, 213-221.

https://doi.org/10.15740/HAS/IJAE/9.2/213-221

[5] Recinos, N., Kallioras, A., Pliakas, F. and Schuth, C. (2015) Application of the GALDIT Index to Assess the Intrinsic Vulnerability to Seawater Intrusion of Coastal Granular Aquifers. Environmental Earth Sciences, 73, 1017-1032.

https://doi.org/10.1007/s12665-014-3452-x

[6] Walther, M., Graf, T., Kolditz, O., Liedl, R. and Post, V. (2017) How Significant Is the Slope of the Sea-Side Boundary for Modeling Seawater Intrusion in Coastal Aquifers? Journal of Hydrology, 551, 648-659. https://doi.org/10.1016/j.jhydrol.2017.02.031 